\title{
Produções Legais da Pirataria: 0 Streaming e a Incorporação das Demandas e Discursos Piratas no Mercado do Entretenimento Digital
}

\author{
ANDRESSA NUNES SOILO
}

Em outubro de 1999, Shawn Fanning - um estudante estadunidense, à época com 19 anos de idade - cria o Napster, um programa de compartilhamento gratuito de músicas - muitas delas protegidas por direitos autorais - encerrado, em seu formato gratuito, no ano de 2001. A criação do site se deu em razão da vontade de Fanning em viabilizar um programa que facilitasse o acesso às músicas $\mathrm{MP}^{1}{ }^{1}$, já que naquele período os sites que permitiam acesso às músicas não ofereciam variedade musical, e eram demasiado lentos - isso em decorrência da centralidade com que somente um servidor alimentava as solicitações de downloads dos usuários, se sobrecarregando. A disponibilização de downloads gratuitos de músicas não era, assim, uma novidade, mas os programas online que ofereciam áudio digital não eram considerados eficientes e exigiam dos internautas conhecimentos técnicos que nem todos possuíam. Tais condições possibilitaram e motivaram a criação do Napster através da tecnologia peer-to-peer $(\mathrm{P} 2 \mathrm{P})^{2}$ - que em português significa "de igual para igual" -, fato que tornou o site um dos mais notáveis serviços de compartilhamento da internet àquela época. Como explica Castro (2001), a programação do Napster basicamente realizava a leitura de arquivos de músicas MP3 em um disco rígido e publicava a lista destes arquivos em um servidor da rede. Quando alguém procurava por alguma música, o buscador do site explorava a requisição nos computadores das pessoas que se encontravam online, mostrando opções de máquinas que continham as músicas, e que eram possíveis de serem com-

$1 \mathrm{O}$ MP3 corresponde a um formato eletrônico de compressão de músicas digitais que permite que os áudios sejam ouvidos em boa qualidade mesmo ocupando espaços pequenos no computador. A qualidade das músicas em MP3 é muito semelhante à qualidade das vendidas em CD’s, o que instiga ainda mais a manifestação de gravadoras sobre o compartilhamento de músicas em tais formatos.

2 A tecnologia P2P corresponde a um formato de rede de computadores que são caracterizados pela descentralização de suas funções, ou seja, os computadores dos usuários realizam simultaneamente as funçôes de servidores e de clientes. O termo "de igual para igual" corresponde, assim, à igualdade de função dos computadores, que não somente recebem, mas também enviam dados a outros usuários aliviando a carga dos servidores centrais. 
partilhadas naquele momento. Assim, quem utilizava o Napster, automaticamente tinha uma lista das músicas que continha em seu computador associada a um banco de dados que podia ser vasculhado por outra pessoa.

No início dos anos 2000, rapidamente o site se populariza, apresentando aproximadamente 14 mil músicas baixadas por minuto; uma estimativa de 75 milhões de usuários registrados (Rayburn 2001); e expansão de cerca de $25 \%$ ao dia de sua base de usuários (Cohen 2000). Nessa época, o termo mais procurado nos sites de busca era "MP3"3; o Napster entra para o Guinness Book of World Records como o empreendimento com crescimento mais rápido de todos os tempos (Bruenger 2016; Nieva 2013); e Shawn Fanning, o criador do programa, estampa a capa da revista Time - uma das revistas de maior circulação do mundo publicada nos Estados Unidos - que considerava seu programa uma das "maiores aplicações da Internet já criadas, juntamente com o e-mail e as mensagens instantâneas" (The Observer 2013). Com sua popularidade, o Napster atraiu, ao longo de sua breve existência, investidores como a Hummer Winblad Venture Partners ${ }^{4}$ e a Bertelsmann 5 . A primeira investiu aproximadamente US\$13.000.000 (Menn 2006) no programa, empossando, em contrapartida, um de seus membros como CEO do serviço; e a segunda, ajudou financeiramente a criação de Fanning em uma monta de US\$100.000.000 (DW 2003), a fim de criar conjuntamente com o Napster um serviço por assinatura que simultaneamente ofereceria downloads gratuitos, e garantiria o pagamento dos direitos autorais a seus detentores (Pellegrini 2000). A popularidade do serviço também despertou a atenção da indústria fonográfica que considerou suas atividades como violadoras de direitos autorais, e promoveu diversas empreitadas legais a fim de retirar o programa do ar - o que consequentemente também levou os investidores do serviço a se perceberem como réus em tribunais, acusados de facilitarem o acesso indevido de milhões de usuários a milhões de músicas (Harmon 2003; Menn 2006).

Os rearranjos desencadeados no campo da propriedade intelectual por programas de compartilhamento de torrents ${ }^{6}$, a partir do final da década de 1990, apresentaram mais do que reações amparadas em punições legais e em publicidades pedagógicas por parte dos detentores dos direitos autorais, também provocaram o surgimento de novos modelos de negócios no mercado digital. Intimamente relacionada ao capitalismo, as relações entre entretenimento e propriedade intelectual se perceberam, nas últimas décadas, reféns das reivindicações e desejos das gerações que sucederam e experienciaram o Napster, gerações essas que acabaram por pressionar o mercado regularizado a harmonizar elementos como baixo custo ao consumidor, lucro e legalidade. Alguns anos após a inatividade da versão gratuita do Napster, a indústria do entretenimento despertou a atenção do público com o lançamento de servi-

3 Os cibernautas não buscavam detalhes técnicos envolvendo o compressor de áudio, mas músicas passíveis de serem baixadas (Witt 2015).

4 Uma empresa de capital de risco que investe, desde 1989, em empresas de software de empreendimento inicial.

5 Uma companhia internacional de mídia que surpreendeu ao anunciar seu investimento junto ao Napster, já que a BMG Entertainment, gravadora da Bertelsmann, estava processando o serviço de música. (Pellegrini 2000).

6 Torrents correspondem a extensões de arquivos que podem ser compartilhadas entre usuários online. 
ços que vendiam legalmente, e a preços considerados, até então, baixos, downloads de música e vídeos, como iTunes Music Store e iTunes Movie Downloads. O primeiro corresponde a um programa que, assim como o Napster, oferece acesso rápido e quantidade ilimitada de downloads de músicas para escolher, mas que, diferentemente da gratuidade da pirataria e da compra física de CD’s que custavam aproximadamente $\$ 15,00$, disponibiliza a seu público downloads a $\$ 0,99^{7}$; já o segundo, oferece o aluguel e a compra de downloads de filmes com preços que variam entre $\$ 0,99$ a $\$ 19,99$ dependendo de características como a qualidade e a data de lançamento das produções ${ }^{8}$. As características de serviços como o iTunes sugerem que o processo de apropriação da resistência da "geração Napter" havia começado em meados dos anos 2000: o baixo preço dos produtos e a liberdade dada ao público em escolher as músicas que queriam ouvir eram demandas de consumidores que experienciaram os rearranjos econômicos proporcionados por programadores de plataformas de compartilhamento de músicas não-autorizadas.

Contudo, as dinâmicas entre novas tecnologias e distribuição e acesso de conteúdo anunciam novos formatos de mercado que (ironicamente ou não) se assemelham e atendem, cada vez mais, às demandas e lógicas piratas. Apesar do sucesso dos serviços iTunes, a venda de downloads tem sofrido decréscimo nos últimos anos (IFPI 2017), muito em razão da emergência do streaming, tecnologia que transmite instantaneamente dados de áudio e vídeo sem a necessidade de esperar a conclusão de um download - já que a exibição de vídeo e áudio são possíveis durante a transferência dos dados?. Na prática, como sugerem Kischinhevsky et al. (2015), o streaming pode ser descrito como "portais de consumo, promoção e circulação de conteúdos sonoros, operando também como mídias sociais" (Kischinhevsky et al. 2015: 303). Pode-se dizer que os serviços de streaming, apesar de tecnologia não recente ${ }^{10}$, representam na atualidade um campo não só de disputas, como mostrarei a seguir, mas também, simultaneamente, um campo de reprodução das práticas e ideais "piratas" e um campo de renovação das expectativas dominantes concernentes ao combate da pirataria digital. Minha escolha em destacar o streaming e não o download legal enquanto expressão da resistência ao poder das indústrias do entretenimento se resume, basicamente, na intensidade com que relacionalidades, similaridades e (con)fusões emergem entre aquela tecnologia e a pirataria digital: os trânsitos entre (i)legalidades, a gratuidade, e as constantes violações (legais e simbólicas) dos direitos autorais me conduziram a tratar o streaming como tecnologia de significativo valor analítico para a observação da resistência e da propriedade intelectual no ciberespaço.

Destaco que os serviços de streaming oferecerem à indústria do entretenimento alguns atrativos que, no ponto de vista da praticidade dos consumidores e da segurança das indústrias, se opõem à

\footnotetext{
7 Na primeira semana de lançamento do iTunes o serviço vendeu um milhão de downloads se tornando o maior distribuidor legalizado de música digital. (Knopper 2013).

8 Em 2007 o iTunes Store se tornou o espaço online mais popular para baixar filmes: aproximadamente 2 milhôes de filmes foram vendidos.

9 Para exibir o conteúdo o computador contata o servidor do serviço que se quer acessar e inicia a realização do download. Os arquivos são salvos no buffer quando existe a quantidade de dados suficiente para que o usuário possa assistir vídeos ou ouvir músicas, e assim a exibição é iniciada. Com as inovações tecnológicas é possível que o usuário nem mais espere o carregamento do buffer para consumir o que deseja, já que o streaming pode se dar através de transferência por meio da internet em fluxo de dados de um servidor até o computador.

10 A tecnologia streaming já existia na década de 1990, mas devido à baixa velocidade das conexões de internet à época, assistir a um vídeo ou ouvir a uma música de modo instantâneo antes da emergência da banda larga não se mostravam enquanto vantagens práticas já que os dados ficavam mais tempo carregando e sendo armazenados do que transmitidos.
} 
operacionalidade do download, como: a) a capacidade de deter os meios técnicos para o controle de produções digitais - impedindo que seus usuários baixem (mantenham salvo o conteúdo) ou distribuam arquivos ${ }^{11}$; e b) a capacidade de atrair o público consumidor através de seu relativo baixo custo e da praticidade de não se ter que esperar o download ser concluído - uma das principais vantagens do streaming sobre o "formato torrent" de consumo. Dentre outras, tais características tornam essas redes intermediárias de atuais modos de consumo a partir de contratos com estúdios e gravadoras que concedem, a esses serviços, licença para o oferecimento de produções de seu repertório. Como instrumento de distribuição legal e digital de entretenimento, as plataformas de streaming apresentam, na atualidade, considerável popularidade em diversos países - serviços como Spotify e Netfilx contam, respectivamente, com 50 milhões e 100 milhões de assinantes em mais de 150 países -, chegando a representar, nos Estados Unidos, maior fonte de rendimentos para a indústria fonográfica em 2016, superando a venda de downloads e de produtos físicos (RIAA Report 2017) ${ }^{12}$. O suposto êxito e a popularidade da tecnologia de streaming também acabaram por desencadear especulações e discussões acerca de sua reverberação no mercado pirata, dividindo a opinião social entre manifestações de anúncios do fim da pirataria a médio e a longo prazo (Thomes 2013), e expressões que defendem o streaming enquanto modelo de negócio que reforçará a permanência do compartilhamento ilegal de conteúdo através da assimilação pirata de tal tecnologia (Borja \& Dieringer 2016; Idland et al. 2015; Smith 2016).

Com as inovações tecnológicas e com novas demandas e percepções do público nos anos 2000, a capacidade dos atores dominantes de responderem de modo satisfatório ao novo cenário foi deslegitimada desencadeando novas estratégias de consumo por parte da indústria. Atenho-me aqui a problematizar a construção dessas novas estratégias de atração do mercado legal de entretenimento através da tecnologia streaming, me atentando às apropriações de resistências ao modelo de consumo tradicional que irromperam após o surgimento do Napster. Atualmente é possível perceber que muitas das estratégias que seduzem simultaneamente consumidores e produtores de entretenimento - atores muitas vezes em conflito, como mostrei - são baseadas em críticas e reivindicações que permearam os conflitos envolvendo os programas de compartilhamento do final da década de 1990. A gratuidade, o baixo custo e o apelo à visibilidade do consumidor (enquanto sujeito detentor de limitado poder econômico e possuidor de desejos) são demandas que fizeram parte de discursos de resistência que protagonizaram as reivindicações de atores que questionavam o formato e as práticas de mercado a partir da pirataria digital, e que hoje podem ser percebidos como incorporados nos modelos de negócios legais.

11 Como lembra Caetano (2016), a diferenciação entre streaming e downloading permeou a história das tecnologias de difusão e emissão de áudio e vídeo com a questão do perdurável e do efêmero: os gravadores de audiocassetes e videocassetes foram perseguidos pela indústria do entretenimento em razão da habilidade técnica em conservar conteúdo.

12 De acordo com a RIAA, o streaming representou a maior fonte de rendimentos $(51,4 \%)$ para a indústria fonográfica nos Estados Unidos no ano de 2016. (RIAA Report 2017). 
Tal redirecionamento estratégico das produtoras de conteúdo não é, contudo, novidade, tampouco soa com novidade a assimilação de resistências "piratas" por tais corporações ${ }^{13}$ (Kernfeld 2011). Em meados das décadas de 1950 e 1960 surgia a televisão como meio de entretenimento doméstico amplamente rejeitado por estúdios de cinema muito em razão da queda nos rendimentos de bilheteria - a indústria até mesmo ameaçava seus atores caso eles participassem de programas de televisão. Contudo, as produtoras logo passaram a perceber a televisão como instrumento útil, capaz de gerar receita sobre filmes antigos que, apesar da demanda, não eram transmitidos pelo formato tradicional de exibição cinematográfica (Lev 2003). Nas décadas de 1970 e 1980 a emergência e a popularidade do VCR (Video Cassette Recorder), aparelho de gravação e reprodução de imagens, também gerou rearranjos no modo de consumo do entretenimento, dessa vez o usuário detinha mais controle sobre o quê e quando assistir: se a televisão oferecia uma grade de programação em que o telespectador detinha pouco poder de escolha, com a então recente tecnologia o telespectador poderia assistir a qualquer conteúdo quando quisesse. Também existiam, ainda que caros, equipamentos que copiavam o conteúdo de uma fita VHS (Video Home System) para outras, processo que, apesar da perda de qualidade após sucessivas cópias, permitia que filmes piratas fossem reproduzidos sem pagamentos de royalties. Em meados de 1980 produtores de filmes e de demais conteúdo, após reagirem de modo a rejeitar as novas tecnologias, passaram a licenciar seus produtos em tal formato assimilando o formato VHS (Alves et al. 2011).

Assimilações e coproduções envolvendo legalidades/ilegalidades no campo das tecnologias de transmissão de entretenimento não são, assim, práticas que denotam novidade nas dinâmicas da distribuição, circulação e acesso a bens, mas sim práticas que se readaptam (em diferentes níveis), às demandas sociais, inovações tecnológicas e competição. Transitando por entre (i)legalidades o consumo legalizado de streaming na atualidade, como no passado, também atualiza e reconfigura o monopólio do entretenimento deslocando questões de valor e de justiça presentes nos fundamentos e nas justificativas de conjuntos de leis (como o regime de propriedade intelectual), e em princípios tradicionais de mercado. Disputas envolvendo o tempo e a capacidade do streaming em lidar com as demandas do mercado tradicional do entretenimento (mercado que pleiteia determinadas bases de lucro), e as capacidades de tal modelo em se estabilizar como recurso rentável e produtor de laços sociais frente ao público, fazem de tal tecnologia um campo de negociações de interesses. O streaming, enquanto nova tecnologia, mobiliza a problematização de categorias como "justiça", "propriedade intelectual” e "pirataria" nas relações de consumo e nos modos de distribuição de entretenimento, muito em razão da violação de direitos autorais, das versões gratuitas dos serviços, e do montante da receita que é destinada aos titulares dos direitos de músicas e vídeos. A WIPO (World Intelectual Property Organization), agência da ONU (Organização das Nações Unidas) especializada em assuntos relativos à propriedade intelectual, assim como artistas e demais detentores de direitos autorais, se manifestam publicamente

13 Kernfeld (2011) faz uma observação valiosa em seu livro sobre o padrão de comportamento dos conflitos envolvendo a indústria do entretenimento e a propriedade intelectual, sempre que novas tecnologias surgem prejudicando os detentores de direitos autorais estratégias de corporações emergem, sejam elas legais ou publicitárias, com pouca ou nenhuma efetividade há casos em que ocorre a assimilação ou a obsolescência: em casos de assimilação os monopólios desistem de resistir às práticas combatidas e incorporam tais práticas criando uma forma legítima delas. 
de modo a reprovar as proporcionalidades consequentes do modelo de negócio aplicados ao serviço de streaming na atualidade. A crítica é direcionada aos sensos de justiça relativos aos rendimentos merecidos e destinados aos artistas que, considerados baixos, são percebidos como instrumentos de injustiça que usurpam o valor econômico e moral do regime de propriedade intelectual ${ }^{14}$.

Neste artigo trato os anseios e demandas da pirataria digital e de seus apoiadores - como a gratuidade, o baixo custo, e a maior autonomia no consumo - enquanto práticas e linguagens apropriadas pela indústria do entretenimento como estratégias de ampliação de mercado. Sendo o ciberespaço, simultaneamente, meu interlocutor, meu campo e minha principal fonte de acesso aos dados, a etnografia que apresento tem como principal meio de investigação (e de razão de ser), o computador. Os dados apresentados aqui foram coleados entre os anos 2015-2017 através de sites de notícias; sites das plataformas analisadas; sites produzidos exclusivamente para protestos ${ }^{15}$; fóruns de discussões; blogs; vídeos; legislações; produções científicas; relatórios; e opiniões e expressões de protestos ocorridos no campo off-line, mas noticiados online. A análise é baseada, principalmente, nas atividades de quatro serviços de streaming de áudio e de vídeo que apresentam, atualmente, considerável popularidade nos meios de consumo: Spotify, Deezer, Netflix, e Amazon Prime Video.

Com base em tais plataformas busco problematizar a questão da apropriação dos discursos e demandas associados ao campo da pirataria (especialmente a partir dos anos 2000) por formatos legais de distribuição de entretenimento, através de duas vias analíticas: a) a via legal que se manifesta nas estratégias de atração do público; b) a via ilegal representada por práticas desempenhadas por serviços não-autorizados, como as violações da propriedade intelectual. Tais caminhos analíticos, apesar de analisados separadamente e de destacarem o binômio legal/ilegal, não devem ser percebidos como itinerários que conduzem a sentidos opostos, mas sim a partir de uma relação de coprodução e coexistência. $\mathrm{O}$ argumento que proponho aqui é o de que o streaming, enquanto modelo de negócio legítimo, é permeado e produzido a partir da apropriação das demandas e discursos da pirataria frente ao modo de mercado tradicional do entretenimento, estabelecendo uma relação de reprodução criativa (a partir) do ilegal. As práticas, ideais e subjetividades que engendraram/engendram os programas de compartilhamento ilegais fazem hoje parte das dinâmicas legítimas do mercado cinematográfico e fonográfico destacando a sujeição à gratuidade e aos baixos preços do consumo e reproduzindo a insatisfação de artistas e demais detentores de direitos autorais, sugerindo um processo que chamo de "legitimação da pirataria”.

$14 \mathrm{O}$ desequilíbrio notado, por vezes, pela indústria do entretenimento é observado através da perspectiva das vendas tradicionais onde os titulares de direitos recebiam uma taxa previamente acordada na venda do produto independentemente se o consumidor ouvisse as músicas. Em contraste, os serviços de streaming oferecem rendimentos aos detentores de direitos autorais se baseando no conteúdo consumido (Rechardt 2015).

15 Alguns sites foram produzidos por simpatizantes e usuários dos programas em questão a fim de protestarem contra as tentativas de controle da indústria do entretenimento, artistas, e Estado sobre os serviços de compartilhamento de arquivos em análise. 


\section{Produções legais da pirataria: estratégias de (in)justiça}

Um artigo publicado no The Wall Street Journal em 2006 intitulado "Free, Legal, and Ignored" (Timiraos 2006) noticiou que mais de 120 universidades estadunidenses, apesar de disponibilizarem músicas gratuitas através de serviços legais de compartilhamento - a fim de impedir que seus alunos consumissem pirataria ${ }^{16}$-, percebiam que seus estudantes continuavam a utilizar programas ilegais disponíveis. A razão principal, conforme o artigo, residia na condição dos usos dos programas legalizados: os estudantes apenas poderiam manter suas músicas até se formarem, o que desmotivou muito alunos, especialmente os prestes a se graduarem, e fez com que algumas instituições acabassem se desvencilhando de tais serviços. Após o efeito do Napster e de sua economia moral - desejos, valores, e moralidades mobilizadas e fundamentadas pela possibilidade de acesso gratuito - ter se alastrado por entre diversos apreciadores do entretenimento instaurando um novo senso de justiça para o mercado e para o consumo, os serviços legais encontraram dificuldades em reconquistar seu público e se estabelecer no mercado. Atualmente, contudo, os serviços de streaming se apresentam engajados em se adaptar ao consumo pós-Napster, acatando (ainda que parcialmente) as reivindicações da geração que experienciou a música "livre", e se concentrando em cativar o público com suas particularidades.

Penso que o "efeito Napster" reconfigurou a indústria do entretenimento não somente no que concerne aos modos de consumir, mas também no que diz respeito aos modos de ofertar o consumo redirecionando as estratégias dos produtores aos desejos e identidades de seus consumidores. $\mathrm{O}$ controverso êxito das plataformas de streaming em conciliarem a "geração pós-Napster", o regime de propriedade intelectual, e a economia capitalista de entretenimento é composto, entre outros elementos, de estratégias inspiradas nos desejos e demandas de acesso gratuito e/ou justo ao longo dos anos 2000, e ainda em curso, que se concentram nas ideias de gratuidade, baixo custo, e acesso a recentes produções. Tais estratégias são percebidas por mim enquanto estratégias de resistência apropriadas por corporações a fim de reaver não somente o público, mas também o controle deste e de suas produções. Percebendo um redirecionamento de prioridades e valorizações dos "atores que produzem" para os "atores que consomem", penso que os novos modelos de negócios baseados em streamings configuram, devido às particularidades que explicitarei a seguir, processos de legitimação de práticas e ideias piratas. Assim, destaco aqui as estratégias apropriadas de quatro populares serviços de streaming da atualidade que cativam com seu baixo custo, praticidade e qualidade: Spotify, Deezer, Netflix e Amazon.

O Spotify e o Deezer são serviços de transmissão online de música criados, respectivamente, por Daniel EK na Suécia em 2008 e por Daniel Marhley na França em 2007. Ambas as plataformas representam, na atualidade, a reaproximação da indústria com o público através da música distribuída de modo legal e, por vezes, paga. Tais plataformas oferecem, a diversos usuários em diversos lugares do

16 Instituições de ensino estadunidenses passaram, em meados dos anos 2000, a oferecer serviços legais de músicas muito em razão da quantidade do consumo da banda larga usada por downloads, já que estes acabavam por bloquear as redes de computadores, e também em razão das ameaças de gravadoras àquela época em tornarem as instituições responsáveis pelos usos ilegais de seus alunos nos espaços de ensino. (Timiraos 2006). 
mundo $^{17}$, não a venda de músicas, mas o acesso a elas. Tais serviços são permeados por dois discursos que sustentam o novo modelo de negócio: o do combate à pirataria e a consequente "proteção" de artistas e de seus trabalhos ${ }^{18}$; e o de seu potencial em diminuir a popularidade dos meios ilegais de acesso a produções. Daniel Ek disse ser inspirado não em programas com serviços similares ao Spotify, mas no combate à pirataria: "I was born in Sweden, and in Sweden we are known for the piracy services [...] I decided I wanted to create a product that was better than piracy." (EK apud Stern 2012).

A popularidade de tais plataformas de streaming ${ }^{19}$ como modelo de negócio legal é associada a algumas de suas características estratégicas de atraírem o público, como versões gratuitas de seus serviços e recursos que visam não somente compreender os gostos musicais do público, mas também o aproximar de seus artistas favoritos. Tais estratégias possuem correlação com as reivindicações populares realizadas nos periodos durante e pós-Napster: a indústria do entretenimento era percebida como egoísta e gananciosa no que diz respeito a suas atitudes frente ao consumidor, não considerando seus desejos e seu limitado poder de compra. Considero a versão freemium do Spotify e do Deezer representativas da apropriação de resistências dos programas de compartilhamento de arquivos como Napster, pois atendem à maior das deman-

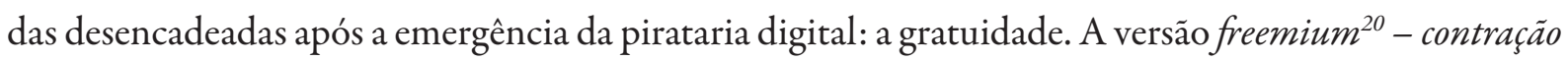
das palavras "gratuito" e "exclusivo" e inglês - écaracterizada pelo acesso livre de custos sendo suportada por publicidade nos intervalos das músicas. Já a versão "premium"se faz atraente ao público por cobrar quantias que variam entre $R \$ 14,90$ (Deezer) e $R \$ 16,00-R \$ 26,90$ (Spotify), valores por vezes mais baratos que pacotes de TV a cabo e ingressos de cinema ${ }^{21}$. Tal estratégia de mercado mantém mais semelhanças com os programas de compartilhamento do que com uma novidade revigorante no mundo da música, parte em razão de suas versóes gratuita e de baixo custo ao assinante, e parte por causa das polêmicas envolvendo a valorização do artista.

Pesquisar sobre as novas tecnologias de streaming e seus desdobramentos no mercado legal de entretenimento oferece o esbarrar com inúmeras notícias e relatos envolvendo a distribuição de ro-

17 Atualmente o serviço se encontra em 58 países, possui, aproximadamente, 50 milhões usuários sendo 12,5 milhões destes assinantes pagantes, e arrecadou bilhões de dólares para seus investidores. (Seabrook 2014).

18 De acordo com o site do Spotify o objetivo de seu serviço é auxiliar fãs de músicas e artistas a se conectarem, protege-los da pirataria, e pagá-los por seu trabalho: "Our whole reason for existence is to help fans find music and help artists connect with fans through a platform that protects them from piracy and pays them for their amazing work. Quincy Jones posted on Facebook that "Spotify is not the enemy; piracy is the enemy". You know why? Two numbers: Zero and Two Billion. Piracy doesn't pay artists a penny - nothing, zilch, zero. Spotify has paid more than two billion dollars to labels, publishers and collecting societies for distribution to songwriters and recording artists. A billion dollars from the time we started Spotify in 2008 to last year and another billion dollars since then. And that's two billion dollars' worth of listening that would have happened with zero or little compensation to artists and songwriters through piracy or practically equivalent services if there was no Spotify - we're working day and night to recover money for artists and the music business that piracy was stealing away." (SPOTIFY ARTISTS 2014).

19 Mesmo com 50 milhões de usuários pagantes localizados em 60 países e com o auxílio de investidores, o formato de negócio do Spotify não o faz rentável - ou rentável como deveria ser considerando seu sucesso -, sendo percebido como um modelo de negócio refém das gravadoras (Shanley 2016). Quando de seu lançamento o serviço não contava com muitos ouvintes, o que o fez arrecadar aproximadamente US\$180 milhões em seus primeiros anos para pagar às marcas adiantamentos de pagamentos de royalties (Constine 2017), e rapidamente se encontrar em prejuízo muito em razão de seus lucros dependerem dos acordos sobre pagamento de royalties com as gravadoras - cerca de $55 \%$ dos rendimentos - e dos pagamentos adicionais para editores de música (Plummer 2017).

20 Contudo, o modelo de negócio do Spotify mantém mais semelhanças com os programas de compartilhamento do que com uma novidade revigorante no mundo da música, parte em razão de suas versões gratuita e de baixo custo ao assinante, e parte por causa das polêmicas envolvendo a valorização do artista.

21 Frequentemente novidades aos usuários são criadas, como o oferecimento do pacote "premium" pela metade do preço (no Brasil R\$ 8,50) a estudantes universitários (Cossetti 2017) 
yalties às gravadoras e aos artistas e o consequente descontentamento de muito atores da indústria do entretenimento com tal modelo de negócio. Isso porque, a gratuidade e o baixo custo dos serviços oferecidos aos consumidores dificilmente tornam as plataformas economicamente sustentáveis para artistas e demais detentores dos direitos autorais. Especulações apontam que os serviços de streaming, após estabelecerem contratos e pagarem a gravadoras grandes quantias de dinheiro a fim de terem acesso legal a seu repertório ${ }^{22}$, pagam menos de um centavo de dólar aos titulares de direitos cada vez que uma música é ouvida ${ }^{23}$. Os contratos entre plataformas de streamings e gravadoras se mostra atualmente obscuro ao público, mas indicam que, apesar de estipularem preços pré-determinados por produções com estúdios e gravadoras, nada é acordado sobre o quanto o artista irá receber desse pagamento. No caso dos artistas independentes, muitos devem pagar para expor seus trabalhos nas plataformas e possivelmente esperar nenhum retorno financeiro - já que é possível que suas músicas sejam acessadas por usuários não pagantes dos serviços. A dinâmica comercial que se apresenta remete à ideia de um programa pirata que comprou os direitos, mas que continua não atendendo aos princípios e necessidades que a propriedade intelectual a produz - como o estímulo criativo, a valorização da criação e do criador, e o retorno financeiro compensatório/satisfatório.

Alguns artistas considerados populares no mundo da música, por exemplo, se recusaram a conceder suas músicas à plataforma Spotify, muito em razão da versão gratuita do serviço e de seu baixo custo que, consequentemente, não produz retorno financeiro considerável, significativo e respeitável para os artistas. A cantora Taylor Swift, antes de retornar recentemente aos catálogos de streaming, foi, em 2014, uma das principais porta-vozes que se opunham a tais serviços, os percebendo como ferramentas que não valorizavam a música e exploravam os artistas (Swift apud Knopper 2014); Jimmy Buffet, músico e empresário, se manifestou pedindo um aumento a Daniel Ek, o CEO do Spotify (Buffet apud Anderson 2014); o cantor Thom Yorke disse, em 2013, que o serviço era "the last desperate fart of a dying corpse" (Yorke apud Dredge 2013); a cantora Joanna Newsom se manifestou dizendo que o "Spotify is like a villainous cabal of major labels." (Newsom apud Roberts 2015); o artista Beck relatou que "What Spotify pays me is not enough to pay the musicians playing with me or the people working on the disks. The model does not work." (Beck apud Finley 2015); e a banda Grizzly Bear publicou em seu Twitter: “[...] Spotify do not help bands or labels or indie stores. Not shaming you, just stating facts since someone asked." (Grizzly Bear Twitter 2012). Artistas independentes também se posicionam de modo a criticar a dinâmica de pagar para compartilhar música de graça: recentemente o artista independente Brett Newski compôs e publicou uma música intitulada "Fuck you Spotify" em que

22 Foi publicado que o Spotify, por exemplo, acordou em pagar U\$25 milhões em dois anos de contrato com a Sony. (Singleton 2015). 23 Em 2016 uma banda compartilhou que ganhou $\$ 4,955.00$ por mais de um milhão de streamings realizados de sua obra (Resnikoff 2016), e o cantor Frejat disse ter recebido $\mathrm{R} \$ 0,33$ por mais de 4,000 execuções de uma música sua (Gould 2016). 
sugere que os atuais modelos de negócio de streaming conjugam injustiças (endereçadas às disposições e eficácias da propriedade intelectual) e desvalorização da arte e do $\operatorname{artista}^{24}$.

Apesar da polêmica envolvendo a indústria do entretenimento e seus atores, as plataformas se empenham, para além da gratuidade e do relativo baixo custo de seus serviços, em cativar o público através de recursos de exclusividade que priorizam os gostos de seus clientes. No Spotify os assinantes do acesso "premium" tem a possibilidade de assistir a shows e a apresentações ao vivo de artistas favoritos ou mais populares através do "Spotify Sessions"; de acessar recursos que mostram comentários sobre as músicas; além de serem apresentados a rádios e playlists que compatibilizam com sua preferência musical - a categoria Teen $Z$ para adolescentes, por exemplo, possui playslists criadas pela Revista Capricho (Capricho 2017); e também há o canal gospel com playlists de músicas do gênero (Deezer a 2016). O Deezer também aposta, para além das versões de acesso gratuito e de baixo preço, no contato mais pessoal com seu público através do "Deezer Sessions", uma proposta que oferece apresentações exclusivas de artistas (Dezzer b 2013); e de parcerias com empresas como a companhias telefônicas e com times de futebol - como o clube brasileiro Flamengo com mais de 35 milhões de torcedores, em que

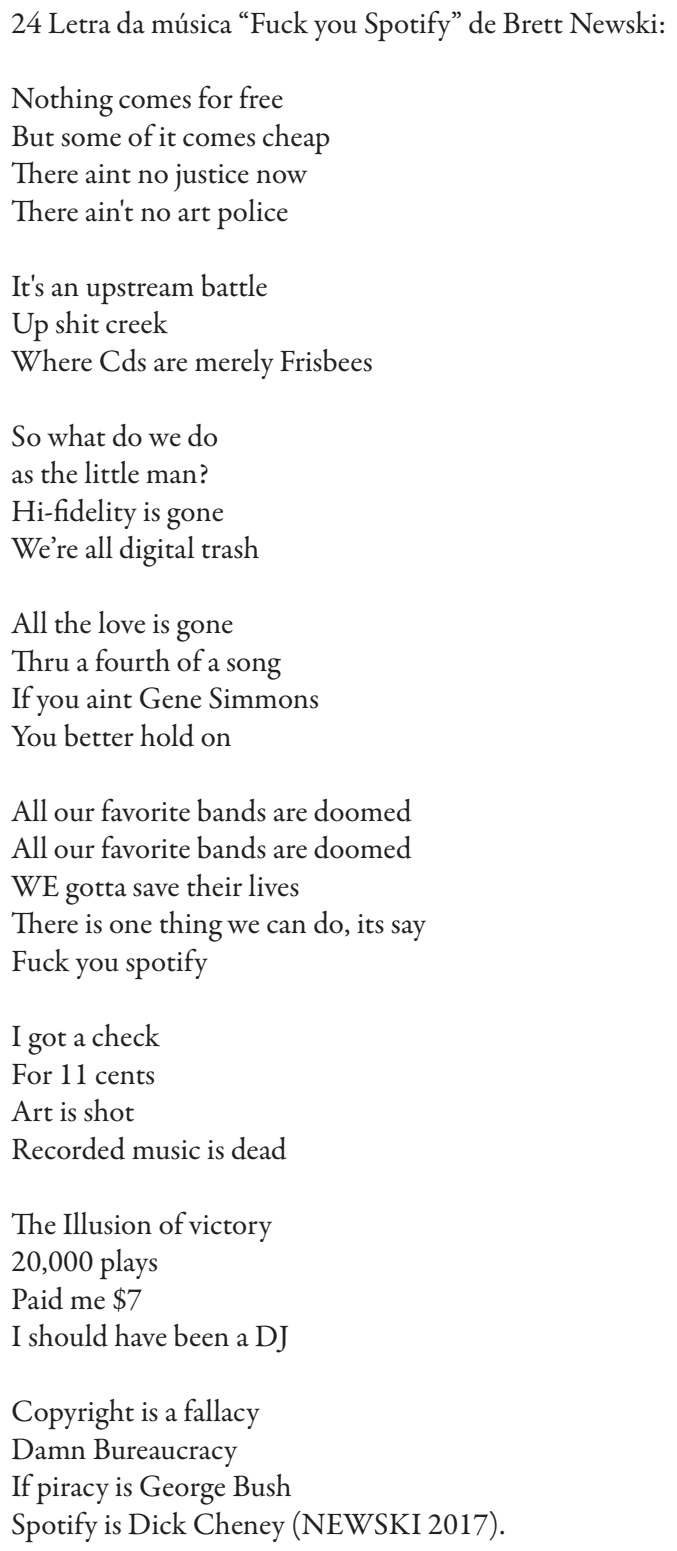


canais oficiais dos clubes são criados apresentando playlists de jogadores, músicas dos anos históricos dos times, entrevistas exclusivas com equipes e narrações de gols -; além de dar suporte a artistas emergentes através do "Deezer Next", iniciativa que auxilia na promoção (e produção) de novos cantores e cantoras através de playlists e demais participações exclusivas na plataforma (Deezer c 2017).

No campo dos filmes, os serviços Netflix ${ }^{25}$ e Amazon Prime Video figuram como os mais conhecidos e utilizados pelo mundo na atualidade alcançando, respectivamente, 100 milhões e 65 milhões de assinantes. Tais serviços oferecem ao público um catálogo de filmes, séries e programas de TV a preço mensal fixo considerado de baixo custo se comparado a pacotes de TV a cabo e ingressos de cinema (a Netflix oferece, no Brasil planos de $\mathrm{R} \$ 19,90, \mathrm{R} \$ 22$, 90, e R $\$ 29,90$, enquanto a Amazon disponibiliza seus serviços a aproximadamente $\mathrm{R} \$ 10,00$ nos primeiros 6 meses e após esse período, $\mathrm{R} \$ 20,00)$. Uma das mais recorrentes objeções frente à tradicional distribuição de produções da indústria cinematográfica residia na desatualização de ofertas em diferentes espaços geográficos - questão que, entre outras, motivou Federico Abad a desenvolver o serviço de streaming Popcorn Time, considerado ilegal por violar direitos autorais -, o que vem sendo tema abordado pela Netflix que se esforça em trazer rapidamente à sua grade de programação filmes recém estreados no cinema. Recentemente a plataforma divulgou que os estúdios irão disponibilizar suas produções no serviço de streaming 45 dias após a estreia nos cinemas - geralmente as produções levam o dobro do tempo para serem disponibilizadas online. (Fritz 2017). Outros exemplos dos esforços de proximidade com o público podem ser visualizados através da possibilidade de os usuários interagirem com as produções da Netflix escolhendo o final das narrativas (Murphy 2017). Já a Amazon Prime Video oferece recursos interativos que permitem ao usuário ter acesso, através de uma ferramenta chamada "Raio-x", que disponibiliza informações de determinadas produções durante a transmissão do vídeo, mais precisamente tal ferramenta viabiliza ao usuário acesso às características dos personagens da produção que está assistindo; o nome, foto e demais filmes e programas em que atores e atrizes participaram; o nome da música que está tocando no momento; a nota que a produção recebeu no IMDb (Internet Movie Database) curiosidades e localizações de cenas particulares (Broida 2016).

Atualmente as estratégias das plataformas de streaming optam por adotarem as demandas dos consumidores que irromperam a partir da "geração Napster", valorizando os desejos e tratando seu público de modo exclusivista/com pessoalidade. Tal estratégia parece, contudo, ser um contraponto à valorização de parte da indústria do entretenimento que percebe os valores econômicos e simbólicos da propriedade intelectual serem subtraídos por novas moralidades e economias de mercado. Penso, assim, que a emergência dos streamings enquanto meios de transmissão podem ser visualizados a partir da perspectiva de incorporação das práticas e da economia moral da pirataria digital, em um processo de assimilação e adaptação que (re)produz novos formatos de mercado.

25 A Netflix, inspirada nas relações por vezes conflituosas entre locadoras e clientes (relações envolvendo multas de atrasos e deslocamentos físicos) foi fundada por Reed Hastings no fim da década de 1990 primeiramente como um serviço online de aluguel de DVD's que, após a solicitação no site, a entrega era efetivada via correio. Em 2007 a empresa apostou no serviço de streaming de transmissão de filmes, seriados e programas de televisão, e com o tempo estabeleceu diversos acordos e parecerias a fim de ampliar seu catálogo de vídeos como, por exemplo, com empresas como Warner Brothers (em 2001), Starz (em 2008), MGM (em 2010), Paramount (em 2010), e Fox (em 2012), além de comprar os direitos de TV da DreamWorks em 2013. 


\section{(Mais) Assimilações, semelhanças e processos de (des)legitimação}

Em se tratando de propriedade intelectual e de tecnologias digitais não é incomum que as fronteiras do ilegal/legal se apresentem borradas, imprecisas, e até como ficção, especialmente quando são abordados os modos online de distribuição e o acesso ao entretenimento. $\mathrm{O}$ próprio co-fundador e CEO da Netflix, Reed Hastings, se manifestou dizendo que a seleção da programação de seu serviço é baseada, entre outros fatores, na popularidade dos downloads piratas, já que estes indicariam quais produções são vantajosas em investir e integrar em seu catálogo (Kelion 2013). Talvez o mais representativo exemplo da mobilidade da (i)legalidade na tecnologia digital seja a trajetória do Napster que, após dois anos ameaçando e reconfigurando substancialmente o poder de mercado da indústria fonográfica através de práticas consideradas piratas, tornou Shawn Fanning, um de seus criadores, um empresário de negócios digitais legítimos: mais especificamente Fanning criou um programa de controle da propriedade intelectual, o Snocap, que auxilia artistas e gravadoras a administrar a distribuição online de suas músicas. O próprio Napster, hoje sem relações com Fanning, se tornou um serviço de streaming de músicas pago, legal, provido de relativa popularidade, e discordante e não-adepto do modelo freemium de outras plataformas. Outros exemplos de "piratas" que também tansitaram/transitam por entre (i) legalidades podem ser percebidos através da trajetória de Peter Sunde, Niklas Zennström e Janus Friis: Sunde, um dos fundadores do The Pirate Bay, criou um sistema de micropagamentos online chamado Flattr, uma plataforma que permite que seus usuários financiem diretamente editores e criadores de conteúdo em uma tentativa de remunerar artistas de modo direto sem o intermédio das indústrias (Sanchez 2017); já Niklas Zennström e Janus Friis, cocriadores do Kazaa - um software que, assim como o Napster também distribuía músicas de modo gratuito e sem autorização no início dos anos 2000, - também criaram o Rdio, um serviço de streaming de música pago e legal.

Apesar de permeados e construídos através/pelo discurso do combate e da eficácia contra a pirataria, as plataformas legais de streaming da atualidade se apresentam muito mais fluídas do que estanques das violações da propriedade intelectual. As (con)fusões entre práticas e sujeitos regulares e irregulares na seara dos direitos autorais são constantes entre tais serviços sugerindo uma dinâmica de coexistência coprodutiva que modela não somente as estratégias de atração do público para a lógica capitalista de consumo, mas também assenta parte das experiências da pirataria na legalidade. Para além das estratégias de apropriação de discursos e demandas da pirataria ao modo de consumo tradicional acabei por me deparar com mais apropriações e similaridades com as experiências e formatos piratas, tais como: o trânsito criativo de atores ilegais/legais para campos legais/ilegais; e as ações judiciais envolvendo violação de direitos autorais que, mesmo com a legitimidade das plataformas, se mostram frequentes.

No campo da música, além do descontentamento de artistas com os rendimentos proporcionados pelos negócios envolvendo a tecnologia streaming, há também, como apontei, o descontentamento envolvendo a observação do cumprimento dos direitos autorais por tais serviços. Ainda que baseados no discurso de combate à pirataria as plataformas de streaming não promovem, para significativa par- 
cela de artistas, rendimentos considerados satisfatórios, nem, por vezes, observam o cumprimento dos direitos autorais. Criadores e demais representantes dos serviços de streaming alegam que as causas para tais violações decorrem dos contratos firmados entre gravadoras e artistas e do descompasso entre tecnologia e lei - as gravadoras não são obrigadas a fornecer informações de suas publicações, como os nomes de compositores e demais envolvidos na produção do conteúdo, o que resulta em um registro incompleto sobre a quem as plataformas devem destinar o crédito autoral.

Apesar das polêmicas envolvendo o retorno financeiro do Spotify aos artistas sua popularidade nutre noções e expectativas de que se trata de uma ferramenta promissora à ameaça da pirataria digital, questão que rendeu a EK o reconhecimento de homem mais poderoso do mundo da música no ano de 2017 pela revista Billboard. Tal revista inicia a apresentação do desenvolvedor em seu artigo do seguinte modo: "For the first time since Napster decimated music sales, the recorded-music industry is showing signs of growth, and that reversal of fortune is largely due to one man: Spotify chairman/ CEO Daniel Ek." (Levine 2017). Contudo, apesar de o CEO do Spotify pagar pouco aos artistas, Daniel EK já transitou por entre os limiares porosos do ilegal chegando a pagar nada aos produtores de conteúdo e lucrar com tal prática quando atuava como co-fundador do uTorrent, um serviço gratuito de distribuição de música suportado por anúncios e controverso sobre sua legalidade (Thetrichordist 2014). Em 2015, o Spotify foi processado pelo músico David Lowery por suposta infração de direitos autorais, alegando que o serviço distribuiu e reproduziu de modo ilegal não somente suas músicas, mas também músicas de outros artistas, sem possuir os direitos mecânicos ${ }^{26}$ para tanto (Sisario 2015). Em 2016 a cantora Melissa Ferrick também processou o Spotify por violação de direitos autorais, alegando que a plataforma disponibiliza, com conhecimento, suas músicas sem autorização ${ }^{27}$.

Assim como o Spotify, as relações da Netflix com o irregular no campo da propriedade intelectual também são fluídas e de coprodução - por vezes o conteúdo ilegal integra o serviço, promovendo e produzindo a plataforma. O serviço já foi acusado de violação de direitos autorais por exibir filmes sem autorização legal (The Guardian 2015). O serviço também acabou por se utilizar de legendas caseiras realizadas por fãs de filmes, esquecendo até mesmo de retirar os créditos de um site que realiza tal atividade (Ernesto 2012) - o que fomentou discussões na internet sobre a relação da indústria do entretenimento com a pirataria ser relativizada quando um serviço legal usa o trabalho de outras pessoas. O serviço de streaming de músicas Pandora foi processado pelas gravadoras Sony, Warner e Universal por infração de direitos autorais em razão do oferecimento de músicas mais antigas que, apesar de não serem protegidas por lei federal, são reguladas por leis estaduais. (Kerr 2014). Mesmo criada para contestar os baixos rendimentos destinados a artistas através de serviços de música como o Spotify, e se posicionando no mercado como uma ferramenta de negócio "a favor dos artistas" a plataforma de streaming Tidal também se envolveu em questões relativas à violação dos direitos autorais de artistas -

26 Direitos mecânicos se referem ao pagamento que o compositor recebe pela reprodução de suas músicas protegidas por direito autoral.

27 Excerto da ação judicial interposta por Melissa Ferrick contra o Spotify: "Spotify did not have and does not have a comprehensive system of music publishing administration in place necessary to license all of the songs embodied in phonorecords which it ingests and distributes by means of interactive streaming and temporary downloads. Rather than decline to distribute phonorecords embodying musical compositions that are unlicensed, however, Spotify elected instead to engage in wholesale copyright infringement." (Ferrick vs. SPOTIFY 2016: 10). 
quando, por exemplo, herdeiros e gravadora do falecido cantor Prince apresentaram processo judicial alegando que tal serviço reproduziu e distribuiu, após o prazo contratual estabelecido, a obra do artista, violando os direitos autorais de seus detentores (Haynes 2016).

Os serviços de streaming da atualidade se esforçam em fazer cumprir a função de atrair e manter no mercado legítimo usuários ilegais, ou seja, aqueles que reivindicam/reivindicam através do uso da pirataria digital e de suas conjunturas novos modos de consumo no entretenimento. Tais esforços se mostram fundamentados na assimilação de demandas políticas da resistência que são adaptadas, técnica e simbolicamente, ao mercado capitalista. As dinâmicas de consumo, neste contexto, se mostram coproduzidas por legalidades e ilegalidades em um processo que, simultaneamente, sugere a legitimação da pirataria e a deslegitimação dos modos tradicionais de mercado. Pistas de tais des/legitimações podem ser observadas não somente a partir da lógica monetária dos pacotes freemium e de baixo custo ofertados consumidor, mas também nos atores que, ao transitarem entre o legal e o ilegal, formam os atuais modelos de streaming, e nas debilidades de tais serviços em cumprirem as regulações do regime de propriedade intelectual.

\section{Considerações Finais}

Os serviços de streaming de transmissão de áudio e vídeo atualmente operacionalizados enquanto intermediários legais de entretenimento ao público são compostos pelas demandas e discursos da pirataria digital que irrompeu com a criação e popularização do Napster, assim como pelas mesmas controvérsias envolvendo a observação legal da propriedade intelectual. Procurei, neste artigo, destacar tais movimentos de incorporação do ilegal ao novo formato do mercado legal de entretenimento digital e consequentemente sugerir que a pirataria constitui parte constituinte e produtora dos atuais meios legais de acesso a áudios e vídeos. O trânsito legal/ilegal que permeia o mercado do streaming que se esforça em cumprir as premissas da propriedade intelectual é, assim, percebido não somente como um desvio, mas como uma força criativa e produtora fundamental nos arranjos do mercado do entretenimento na atualidade.

Andressa Nunes Soilo é doutoranda e mestre em Antropologia Social pela Universidade Federal do Rio Grande do Sul (UFRGS).

\section{REFERÊNCIAS BIBLIOGRÁFICAS}

ALVES, Simone; DIAS, Pedro; NOGUEIRA, Antonio; FIGUEIREDO, Kléber. 2011. Webfilmes: Aluguel de Filmes em Tempos de Pipoca Virtual. In.: ANPAD, Curitiba, v.1, n.2, p.68-85.

BECK apud FINLEY, Jillian. 2015. 9 Artists Reveal Why You Won't Find Their Music on Spotify. In.: MyDomaine. Disponível em: < http://www.mydomaine.com/artists-who-refused- 
-to-stream-music> Acesso em: 20, abr, 2017.

BORJA, Karla; DIERINGER, Suzanne. 2016. Streaming or Stealing? The complementary features between music streaming and music piracy. In.: Journal of Retailing and Consumer Services. Disponível em: http://www.sciencedirect.com/science/article/pii/S0969698916301849 Acesso em: 17, abr, 2017.

BROIDA, Rick. 2016. Everything you need to know about Amazon X-Ray for TV shows and movies. In.: CNET. 20, jun, 2016. Disponível em: https://www.cnet.com/how-to/everything-you-need-to-know-about-amazon-x-ray-for-tv-shows-and-movies/ Acesso em: 25, abr, 2017.

BRUENGER, David. 2016. Making Money, Making Music: History and Core Concepts. University of California Press.

BUFFET, Jimmy apud ANDERSON, Lessley. 2014. Jimmy Buffet asks Spotify CEO Daniel EK for a Raise. In.: Vanity Fair. Disponível em: < http://www.vanityfair.com/news/ tech/2014/10/jimmy-buffett-spotify-ceo-raise $>$ Acesso em: 20, abr, 2017.

CAETANO, Miguel Afonso. 2016. Spotify e os Piratas: em busca de uma "jukebox celestial" para a diversidade cultural. In.: Revista Crítica de Ciências Sociais, 109, 2016. Disponível em: < https://rccs.revues.org/6311> Acesso em: 18, abr, 2017.

CAPRICHO, Revista. 2017. Vem ouvir a playlist especial da CAPRICHO no Spotify. In.: Revista Capricho - Redação, 18, abr, 2017. Disponível em: http://capricho.abril.com.br/famosos/ vem-ouvir-a-playlist-especial-da-capricho-no-spotify/ Acesso em: 20, abr, 2017.

CASTRO, Gisela G.S. 2001. O Caso Napster: Direitos de Propriedade Intelectual em Questão. INTERCOM - Sociedade Brasileira de Estudos Interdisciplinares da Comunicação XXIV Congresso Brasileiro da Comunicação - Campo Grande/MS, 2001.

COSSETTI, Melissa Cruz. 2017. Spotify Premium corta preço pela metade para estudantes no Brasil. In.: Techtudo. Disponível em: http://www.techtudo.com.br/noticias/2017/04/spotify-premium-corta-preco-pela-metade-para-estudantes-no-brasil.ghtml Acesso em: 20, abr, 2017

DEEZERa. 2016. Deezer faz investimento inédito no Gospel para acelerar a adoção do Streaming no Brasil. In.: Deezer Blog. 11, out, 2016. Disponível em: < http://www.deezer-blog. $\underline{\mathrm{com} / \mathrm{br} / 2016 / 10 / 11 / \text { deezer-faz-investimento-inedito-no-gospel-para-acelerar-a-adocao-do-strea- }}$ ming-no-brasil/> Acesso em: 25, abr, 2017.

DEEZERb. 2013. Deezer apresenta: Deezer Sessions. In.: Deezer Blog. 15, out, 2013. Disponível em: < http://www.deezer-blog.com/br/2013/10/15/deezer-apresenta-deezer-sessions/> Acesso em: 25 abr, 2017.

DEEZERc. 2017. Conheça a seleção de artistas brasileiras que fazem parte do programa 'Deezer Next'. In.: Deezer Blog. 8, mar, 2017. Diponível em: http://www.deezer-blog.com/ 
$\underline{\mathrm{br} / 2017 / 03 / 08 / \text { conheca-a-selecao-de-artistas-brasileiras-que-fazem-parte-do-programa-deezer-ne- }}$ xt/ Acesso em: 25, abr, 2017

DW, 2003. Napster é o pesadelo da Bertelsmann. In.: DW. Disponível em: < $\underline{\text { http://www.dw. }}$ com/pt-br/napster-\%C3\%A9-o-pesadelo-da-bertelsmann/a-887545> Acesso em: 14, dez, 2016.

CONSTINE, Josh. 2017. How Spotify is finally gaining leverage over record labels. In.: Techcrunch. Disponível em: https://techcrunch.com/2017/03/18/dictate-top-40/ Acesso em: 18, abr, 2017.

ERNESTO. 2012. Netflix Caught Using "Pirated" Subtitles in Finland. In.: TorrentFreak. Disponível em: < https://torrentfreak.com/netflix-caught-using-pirated-subtitles-in-finland-121019/> Acesso em: 20, abr, 2017.

EK, Daniel apud STERN, Joanna. 2012. Spotify Founder Daniel Ek Wanted to Create Something 'Better than Piracy'. In.: ABC News. Disponível em: < http://abcnews.go.com/blogs/ technology/2012/12/spotify-founder-daniel-ek-wanted-to-create-something-better-than-piracy/> Acesso em: 18, abr, 2017.

FERRICK vs. SPOTIFY, 2016. United States District Court Central Distric of California. Disponível em: https://musictechpolicy.files.wordpress.com/2010/09/ferrick-v-spotify-complaint-filed-1-8-16-1.pdf Acesso em: 20, abr, 2017.

FRITZ, Bem. 2017. From Multiplex to Living Room, in 45 Days or Less. In.: The Wall Street Journal. 26, mar, 2017. Disponível em: https://www.wsj.com/articles/from-multiplex-to-living-room-in-45-days-or-less-1490532001 Acesso em: 25, abr, 2017.

GOULD, Luiza. 2016. Streaming na indústria cultural é tema de debate na OAB/RJ com Frejat e representante do Spotify. In.: O Globo. Disponível em: http://oglobo.globo.com/cultura/streaming-na-industria-cultural-tema-de-debate-na-oabrj-com-frejat-representante-do-spotify-16483339 Acesso em: 29, abr, 2017.

GRIZZLY BEAR TWITTER, 2012. Mog and Spotify do not help bands or labels or indie stores. Not shaming you, just stating the facts since someone asked. In.: Twitter@grizzlybear. Disponível em: < https://twitter.com/grizzlybear/status/241581268242952192> Acesso em: 20, abr, 2017.

HARMON, Amy. Universal Sues Bertelsmann Over Ties to Napster. In.: The New York Times. Disponível em: http://www.nytimes.com/2003/05/13/business/universal-sues-bertelsmann-over-ties-to-napster.html Acesso em: 14, dez, 2016.

HAYNES, Suyin. 2016. Prince's Estate Sues Jay Z's Tidal in Streaming Fight. In.: Time, 16, nov, 2016. Disponível em: http://time.com/4573309/tidal-prince-jay-z-lawsuit/ Acesso em: 02, maio, 2017. 
IDLAND, Elisabeth; ØVERBY, Harald; AUDESTAD, Jan A. 2015. Economic Markets for Video Streaming Services: A Case Study of Netflix and Popcorn Time. In.: Norsk Informatikkonferanse - NIK. Disponível em: < http://ojs.bibsys.no/index.php/NIK/article/view/244 $>$ Acesso em: 17, abr, 2017.

IFPI. 2017. IFPI Global Music Report 2017. In.: IFPI News, 25, abr, 2017. Disponível em:

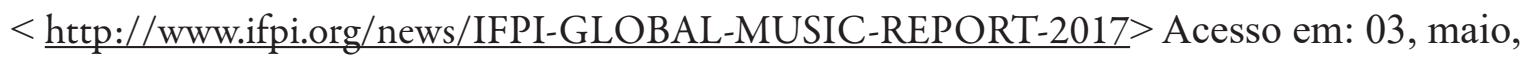
2017.

KELION, Leo. 2013. Netflix studies piracy sites to decide what to buy. In.: BBC News. Disponível em: http://www.bbc.com/news/technology-24108673 Acesso em: 20, abr, 2017.

KERNFELD, Barry. 2011. Pop Song Piracy: Disobedient Music Distribution Since 1929. Chicago, MI: University of Chicago Press.

KERR, Dara. 2014. Pandora sued by record labels for copyright infringement. 17, abr, 2014. In.: CNET. Disponível em: https://www.cnet.com/news/pandora-sued-by-major-record-labels-for-copyright-infringement/ Acesso em: 26, abr, 2017.

KISCHINHEVSKY, Marceloet al. 2015. Em busca da música infinita: os serviços de streaming e os conflitos de interesse no mercado de conteúdos digitais. In.: Revista Fronteiras Estudos Midiáticos, 17 (3), 2015. Disponível em: http://revistas.unisinos.br/index.php/fronteiras/article/view/fem.2015.173.04/4990 Acesso em: 28, abr, 2017.

KNOPPER, Steve. 2013. iTunes' 10th Anniversary: How Steve Jobs Turned the Industry Upside Down. In.: Rolling Stone, 26, abr, 2013. Disponível em: < $\underline{\text { http://www.rollingstone.com/ }}$ music/news/itunes-10th-anniversary-how-steve-jobs-turned-the-industry-upside-down-20130426> Acesso em: 03, maio, 2017.

LEV, Peter. 2003. The American Film Industry in the Early 1950s. In.: The Fifties -Transforming the Screen, 1950-1959. University of California Press, 2003.

LEVINE, Robert. 2017. Billboard Power 100's New No 1: Spotify Streaming Pioneer Daniel Ek. In.: Billboard. Disponível em: < http://www.billboard.com/articles/business/7685308/no-1-power-100-daniel-ek-spotify> Acesso em: 18, abr, 2017.

MENN, Joseph. 2006. Financiers agree to settle Napster suit. In.: Los Angeles Times. Disponível em: < http://articles.latimes.com/2006/dec/13/business/fi-napster13 > Acesso em: 14, dez, 2016.

MURPHY, Margi. 2017. PICK AND NETMIX Netflix could let viewers choose how their favourite shows end using their remote control. In.: The Sun, 06, mar, 2017. Disponível em: https://www.thesun.co.uk/news/3022532/netflix-could-let-viewers-decide-how-their-favourite-shows-end-using-their-remote-control/ Acesso em: 03, maio, 2017. 
NEWSKI, Brett. 2017. Fuck you Spotify. In.: SoundCloud. Disponível em: < https://soundcloud.com/brett-newski/fuck-you-spotify-1> Acesso em: 26, abr, 2017.

NEWSOM, Joanna apud ROBERTS, Randall. 2015. Joanna Newsom calls Spotify 'a villainous cabal' and 'a garbage system'. In.: Los Angeles Times. Disponível em: http://www.latimes. com/entertainment/music/posts/la-et-ms-joanna-newsom-spotify-villainous-cabal-garbage-system-20151015-story.html Acesso em: 20, abr, 2017.

PELLEGRINI, Frank. 2000. BMG and Napster: If You Can't Beat 'Em, Buy 'Em!. In.: Time.

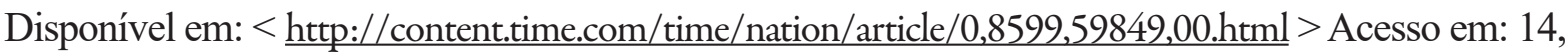
dez, 2016.

PLUMMER, Robert. The clock is ticking for Spotify. In.: BBC News. Disponível em: http:// www.bbc.com/news/business-38930699 Acesso em 18, abr, 2017.

RAYBURN, Corey. 2001. After Napster. In.: Virginia Journal of Law and Technology. Disponível em: <http://www.vjolt.net/vol6/issue3/v6i3-a16-Rayburn.html\#_edn1> Acesso em: 13, jan, 2017.

RECHARDT, Lauri. 2015. Streaming and Copyright: a Recording Industry Perspective. In.: WIPO Magazine. Disponível em: < http://www.wipo.int/wipo magazine/en/2015/02/article 0001.html> Acesso em: 21, abr, 2017.

RESNIKOFF, Paul. 2016. My Band Has 1,000,000 Spotify Streams. Want to See Our Royalties?. In.: Digital Music News. Disponível em: http://www.digitalmusicnews.com/2016/05/26/ band-1-million-spotify-streams-royalties/ Acesso em: 29, abr, 2017.

RIAA REPORT. 2017. News and Notes on 2016 RIAA Shipment and Revenue Statistics 2016. In.: RIAA REPORT Disponível em: < http://www.riaa.com/wp-content/ uploads/2017/03/RIAA-2016-Year-End-News-Notes.pdf $>$ Acesso em: 03, maio, 2017.

SANCHEZ, Daniel Adrian. 2017. The Guy Who Started The Pirate Bay Is Now a Millionaire. In.: Digital Music News. 06, abr, 2017. Disponível em: http://www.digitalmusicnews. com/2017/04/06/adblock-plus-the-pirate-bay-flattr/ Acesso em: 29, abr, 2017.

SHANLEY, Mia. 2016. Spotify could become profitable in 2017. In.: Business Insider. Disponível em: http://www.businessinsider.com/r-exclusive-europes-biggest-tech-hope-spotify-starts-talking-about-profit-2016-12 Acesso em: 18, abr, 2017.

SINGLETON, Micah. 2015. This was Sony Music's contract with Spotify. In.: The Verge. Disponível em: http://www.theverge.com/2015/5/19/8621581/sony-music-spotify-contract Acesso em: 29, abr, 2017.

SISARIO, Bem. 2015. David Lowery Sues Spotify for Copyright Infringement. In.: The New York Times. 29, dez, 2015. Disponível em: https://www.nytimes.com/2015/12/30/business/me- 
dia/david-lowery-sues-spotify-for-copyright-infringement.html?_r=0 Acesso em: 20, abr, 2017.

SMITH, Emma. 2016. Has Netflix Made Piracy Worse? In.: Redpoints Blog. Disponível em: http://blog.redpoints.com/en/netflix-and-piracy-streaming Acesso em: 17, abr, 2017.

SWIFT, Taylor apud KNOPPER, Steve. 2014. Taylor Swift Pulled Music From Spotify for 'Superfan Who Wants to Invest,' Says Rep. In.: Rolling Stone. Disponível em: < http://www. rollingstone.com/music/news/taylor-swift-scott-borchetta-spotify-20141108> Acesso em: 20, abr, 2017.

THE GUARDIAN. 2015. Netflix sued for streaming Bicycle Thieves 'without copyright'. In.: The guardian. Disponível em: < https://www.theguardian.com/film/2015/oct/23/netflix-bicycle-thieves-sued-copyright-streaming > Acesso em: 20, abr, 2017.

THE TRICHORDIST. 2014. A Tale of Two Pirates? Daniel Ek (uTorrent) and Kim Dotcom (Megaupload). In.: The Trichordist - Artists For An Ethical and Sustainable Internet \#StopArtistExploitation, 06, out, 2014. Disponível em: https://thetrichordist.com/2014/10/06/a-tale-of-two-pirates-daniel-ek-utorrent-and-kim-dotcom-megaupload/ Acesso em: 29, abr, 2017.

TIMIRAOS, Nick. 2006. Free, Legal and Ignored. In.: The Wall Street Journal. 06, jul, 2006. Disponível em: https://www.wsj.com/articles/SB115214899486099107 Acesso em: 27, abr, 2017.

THE OBSERVER. 2013. Napster: o dia em que a música foi libertada. In.: Carta Capital. Disponível em: < http://www.cartacapital.com.br/internacional/napster-o-dia-em-que-a-musica-foi-libertada $>$ Acesso em: 12, jan, 2016.

THOMES, Tim Paul. 2013. An Economic Analysis of Online Streaming Music Services. In.: Information Economics and Policy. Dsponível em: http://www.sciencedirect.com/science/article/pii/S0167624513000103 Acesso em: 17, abr, 2017.

YORKE, Thom apud DREDGE Stuart. 2013. Thom Yorke calls Spotify 'the last desperate fart of a dying corpse'. In.: The Guardian. Disponível em: https://www.theguardian.com/technology/2013/oct/07/spotify-thom-yorke-dying-corpse Acesso em: 20, abr, 2017.

WITT, Stephen Richard. 2015. How Music Got Free: A Story of Obsession and Invention. New York: Penguin Books. 


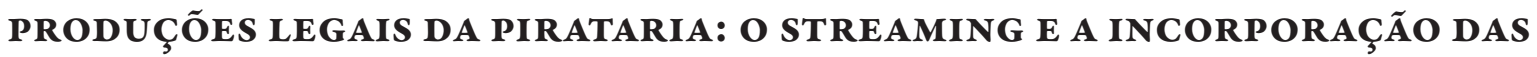 DEMANDAS E DISCURSOS PIRATAS NO MERCADO DO ENTRETENIMENTO DIGI- TAL}

Resumo: A partir das mudanças desencadeada nas indústrias fonográfica e cinematográfica em razão das tecnologias digitais de compartilhamento de arquivos que desafiaram o regime de propriedade intelectual no final da década de 1990, este artigo tem como objetivo analisar processos de incorporação dos discursos e demandas da "pirataria" no mercado legal do streaming. Com base em etnografia realizada no ciberespaço entre os anos de 2015 e 2017 sugiro que as atuais plataformas de streaming são não somente inspiradas, mas permeadas e produzidas pela "pirataria" digital e por suas estratégias de resistência ao mercado tradicional do entretenimento. Em uma dinâmica porosa de produção do legal a partir da incorporação do ilegal é possível dizer que os novos modelos de mercado do entretenimento digital correspondem a processos de formalização das demandas e discursos piratas.

Palavras-chave: Pirataria; Propriedade Intelectual; Cibercultura; Streaming

\section{LEGAL PRODUCTIONS OF PIRACY: STREAMING SERVICES AND ASSIMILATION OF PIRATE DEMANDS AND DISCOURSES IN THE DIGITAL ENTERTAINMENT MARKET}

Abstract: From the changes unleashed in the phonographic and film industries due to digital file-sharing technologies that challenged the intellectual property regime in the late 1990s, this article aims to analyze processes of incorporating the discourses and demands of "piracy" in the legal streaming market. Based on ethnography executed in cyberspace between the years 2015 and 2017, I suggest that today's streaming platforms are not only inspired but permeated and produced by digital "piracy" and their strategies of resistance to the traditional entertainment market. In a porous dynamic of production of the legal from the incorporation of the illegal one can say that the new models of market of the digital entertainment correspond to processes of formalization of pirate demands and speeches. Keywords: Piracy, Intellectual Property, Cyberculture, Streaming

RECEBIDO: 09/10/2017

APROVADO: $12 / 02 / 2018$ 